Jurnal Media Pertanian Vol. 4 No. 1 Tahun 2019 Hal. 1 - 7

Media Komunikasi Hasil Penelitian dan Review Literatur Bidang Ilmu Agronomi ISSN print $2503-1279$

ISSN online $2581-1606$

\title{
SURVEI SERANGAN HAMA PADA PERKEBUNAN TEBU (Saccharum officinarum L.) DI PROVINSI JAMBI
}

\author{
Rizaldi Adrian ${ }^{1}$, Nasamsir $^{2}$, dan Araz Meilin ${ }^{2}$ \\ ${ }^{1}$ Alumni Program Studi Agroteknologi, Fakultas Pertanian Univ. Batanghari \\ ${ }^{2}$ Program Studi Agroteknologi Fakultas Pertanian Univ. Batanghari \\ Jl. Slamet Riyadi, Broni Jambi, 36122. Telp. +62741 60103 \\ e-mail korensponden: nasamsirsamsir@yahoo.co.id
}

\begin{abstract}
Sugarcane is a source of the main ingredients for making sugar, one of the primary needs whose demand is increasing every year. Efforts to increase sugarcane productivity are also constrained by attacks by various pests which cause high economic losses. Some obstacles have caused farmers to fail in controlling pest insects because farmers still have not properly identified insect pests and attack symptoms. This research was conducted in Sungai Asam Village, Siulak Kecil Hilir Village, Hamparan Sungai Bermas, Kerinci Regency, Tangkit Village, Muaro Jambi Regency and Sungai Buluh Village, Batanghari Regency. The method of sampling is done by relative methods, using trapping tools, namely yellow traps and pitfall traps. Insect catches are identified in the laboratory. The results of the identification showed that the Beetle (Rhabdoscelus obscurus) (family Curculionidae) and subfamily Rhynchophorinae (Order Coleoptera), indicated that the main pest was the cause of sugarcane stem borer attacks on the study site. This pest is also known as Uret pests which damage the inside of the stem of sugarcane plants causing death.
\end{abstract}

Keywords: sugar cane, Rhabdoscelus obscures. Rhynchophorinae

\begin{abstract}
Abstrak
Tebu adalah sumber bahan utama pembuatan gula, salah satu kebutuhan primer yang permintaannya selalu meningkat setiap tahun. Upaya peningkatan produktivitas tanaman tebu juga terkendala oleh serangan berbagai hama yang menyebabkan kerugian ekonomi tinggi. Beberapa kendala yang menyebabkan gagalnya petani dalam mengendalikan serangga hama karena petani masih belum melakukan identifikasi serangga hama dan gejala serangan dengan baik. Penelitian ini dilaksanakan di Desa Sungai Asam, Desa Siulak Kecil Hilir, Hamparan Sungai Bermas, Kabupaten Kerinci, Desa Tangkit Kabupaten Muaro Jambi dan Desa Sungai Buluh Kabupaten Batanghari. Metode pengambilan sampel dilakukan dengan metode nisbi yaitu menggunakan alat-alat perangkap , yaitu perangkap kuning (yellow trap) dan perangkap jebakan (pitfall trap). Hasil penangkapan serangga diidentifikasi di laboratorium. Hasil identifikasi menunjukkan bahwa Kumbang (Rhabdoscelus obscurus) (family Curculionidae) dan subfamily Rhynchophorinae (Ordo Coleoptera), diindikasikan merupakan hama utama penyebab serangan penggerek batang tebu pada lokasi penelitian. Hama ini dikenal juga hama uret yang merusak bagian dalam batang tanaman tebu sehingga menyebabkan kematian.
\end{abstract}

Kata Kunci : tanamana Tebu, Rhabdoscelus obscures. Rhynchophorinae

Diterbitkan oleh Program Studi Agroteknologi Fakultas Pertanian Universitas Batanghari Jambi Halaman 1 
Jurnal Media Pertanian Vol. 4 No. 1 Tahun 2019 Hal. 1 - 7

Media Komunikasi Hasil Penelitian dan Review Literatur Bidang Ilmu Agronomi

\section{PENDAHULUAN}

Tanaman tebu (Saccharum officinarum L.) adalah anggota familia rumputrumputan (Graminae) yang merupakan tanaman asli tropika basah namun masih dapat tumbuh baik dan berkembang di daerah subtropika, pada berbagai jenis tanah dari daratan rendah hingga ketinggian $1.400 \mathrm{~m}$ diatas permukaan laut (dpl) (Epati, 2012). Tebu merupakan jenis tanaman monokotil yang dibudidayakan sebagai tanaman penghasil gula. Tanaman tebu diperbanyak secara vegetatif dalam bentuk bagal, namun pada saat ini berkembang metode pembibitan mata ruas tunggal, dan mata tunas tunggal (Rokhman, Taryono, dan Supriyana, 2014). Indonesia merupakan salah satu negara yang strategis untuk pengembangan komoditas perkebunan tebu (Saccharum officinarum L.) karena Indonesia memiliki iklim tropis yang sesuai dengan syarat tumbuh tanaman tebu (Indrawanto, Purwono, Siswanto, Syakir, dan Rumini, 2010). Data luas lahan tebu di Indonesia dari tahun 2012 hingga 2015 menurut Direktorat Jenderal Perkebunan Indonesia (2014) pada tahun 2012 adalah 451.255 ha, pada tahun 2013469.095 ha, tahun 2014 sebesar 477.881 ha dan pada tahun 2015 adalah 487.095 ha. Luas perekebunan tebu di Provinsi Jambi 2012-2015 menurut Data Base Potensi Komoditi Industri Agro (2017) pada tahun 2012-2013 adalah seluas 2.665 ha, 2014 seluas 1.623 dan 2015 seluas 1.664 ha.

Tebu adalah sumber bahan utama pembuatan gula. Gula merupakan kebutuhan primer yang permintaannya selalu meningkat setiap tahun. Kendala yang masih dihadapi oleh industri gula yaitu produksi gula yang masih rendah jika dibandingkan dengan kebutuhanya (Yukamgo dan Yunowo, 2007) dalam Arista et al, (2015).

Produktivitas tebu nasional pada tahun 2017 diperkiraan 5,4 $\mathrm{t} \mathrm{ha}^{-1}$ dengan rendemen 7,5\% sampai $8 \%$. Upaya peningkatan produktivitas tanaman tebu juga sering terkendala oleh serangan hama. Hama pada tanaman tebu menyebabkan penurunan produktivitas gula sekitar $10 \%$. Hama penting penggerek tanaman tebu yang menyebabkan kerugian ekonomi tinggi ialah penggerek pucuk, penggerek batang bergaris, penggerek batang berkilat, dan penggerek batang raksasa (Subiyakto, 2016). Untuk memberi informasi tentang hama tanaman tebu di Provinsi Jambi, telah dilakukan penelitian identifkasi jenis hama yang menyerang tanaman tebu.

\section{METODE PENELITIAN}

Penelitian ini menggunakan metode survey dengan melakukan pengamatan secara langsung pada tanaman yang mengalami serangan atau menunjukkan gejala serangan hama. Pengambilan tanaman sampel menggunakan metode sampling sistemik dengan rumus $K=\frac{\mathrm{N}}{\mathrm{n}}$ ( $\mathrm{N}=\mathrm{jumlah}$ populasi dan $\mathrm{n}=$ jumlah sampel).Pengamatan dilakukan pada luasan 1 ha atau menyesuaikan dengan kondisi pertanaman yang ada dan masing-masing lokasi diamati 3 petak contoh dengan ukuran $10 \mathrm{~m} \times 10 \mathrm{~m}$.

Pengamatan gejala serangan dan pemasangan perangkap dilakukan pada tanaman sampel untuk masing-masing petak contoh. Metode pengambilan sampel 
Jurnal Media Pertanian Vol. 4 No. 1 Tahun 2019 Hal. 1 - 7

Media Komunikasi Hasil Penelitian dan Review Literatur Bidang Ilmu Agronomi ISSN print $2503-1279$

ISSN online $2581-1606$

hama dilakukan dengan metode nisbi yaitu menggunakan alat perangkap. Perangkap yang digunakan adalah ;

1.perangkap kuning yang terbuat dari plastik kuning berukuran $20 \times 20 \mathrm{~cm}$ diberi tiang dan lem kuning. Perangkap ditempatkan selama lebih kurang 1 minggu atau $7 \times 24$ jam dan dievaluasi jenis dan jumlah serangga yang tertangkap.

2. perangkap jebakan untuk mengevaluasi serangga yang menyerang bagian perakaran tebu, terbuat dari gelas plastik yang diisi alkohol 20\% dan setetes larutan sabun. Perangkap diletakkan di dalam tanah (sama tinggi dengan permukaan tanah) selama 2 hari.

\section{HASIL DAN PEMBAHASAN}

\section{Gejala Serangan Hama Pada Tanaman Tebu}

Hasil pengamatan di tiga lokasi Desa Sungai Asam ditemukan gejala serangan hama yang berbeda, lokasi Desa Sungai Asam 1 ditemukan gejala tanaman tebu mati pada bagian tunas, batang tebu rebah, serta terdapat lubang pada bagian batang (Gambar 1a.). Lokasi Sungai Asam 2, ditemukan gejala batang tebu berlubang pada setiap bagian buku batang (Gambar 1b.). Pada lokasi Sungai Asam 3, hanya ditemukan gejala serangan batang berlubang (Gambar 1c.).

Hasil pengamatan di Desa Siulak ditemukan serangan hama dengan gejala adanya lubang-lubang pada setiap bagian buku batang dan pangkal batang tebu (Gambar 1d.).

Hasil pengamatan di Desa Tangkit ditemukan serangan hama dengan gejala menunjukkan adanya lubang-lubang pada batang tebu dan banyak ditemukan pertumbuhan tebu membengkok (Gambar 1e.).

Pengamatan di Desa Sungai Buluh ditemukan tanaman tebu yang menunjukkan pertumbuhan yang kerdil dan gejala serangan hama adanya lubanglubang kecil pada bagian batang tebu (Gambar 1f.)

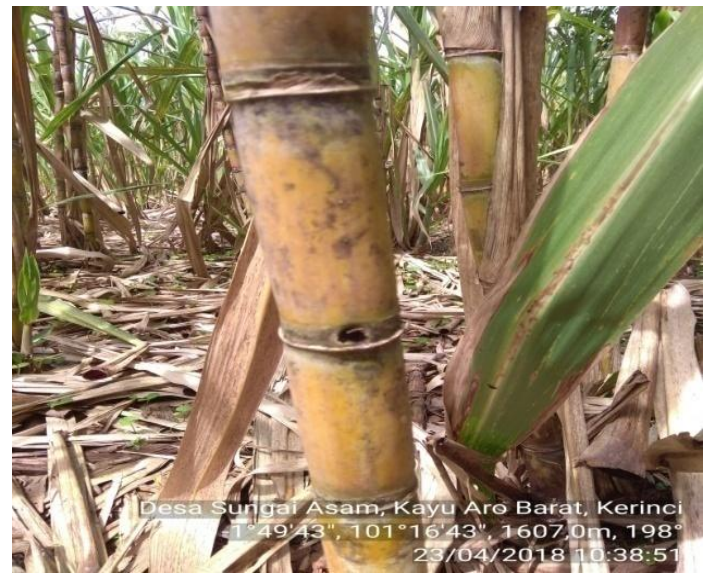

a. Desa Sungai Asam 1

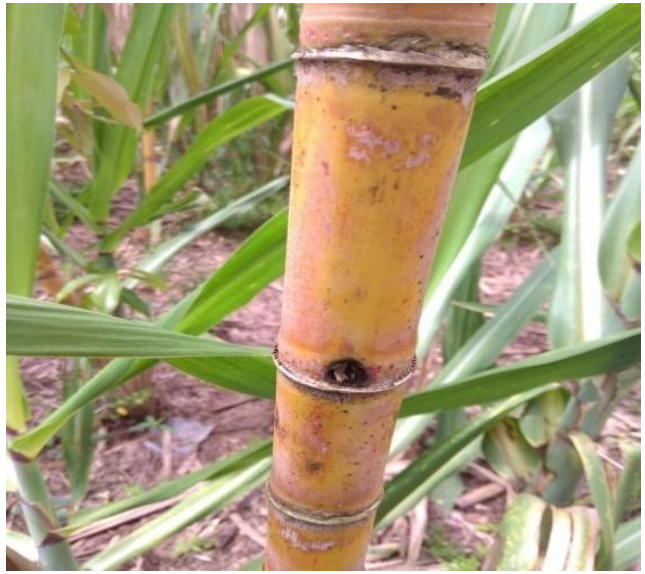

b. Desa Sungai Asam 2 
Jurnal Media Pertanian Vol. 4 No. 1 Tahun 2019 Hal. 1 - 7

Media Komunikasi Hasil Penelitian dan Review Literatur Bidang Ilmu Agronomi ISSN print $2503-1279$

ISSN online $2581-1606$

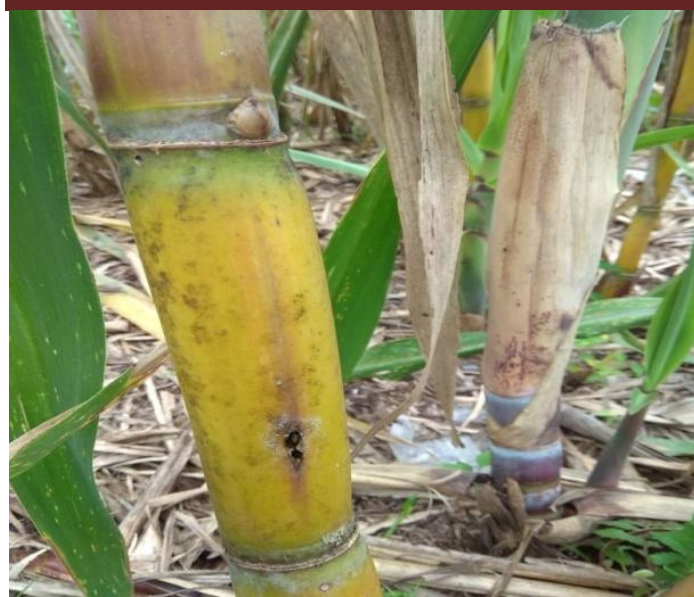

c. Desa Sungai Asam 3

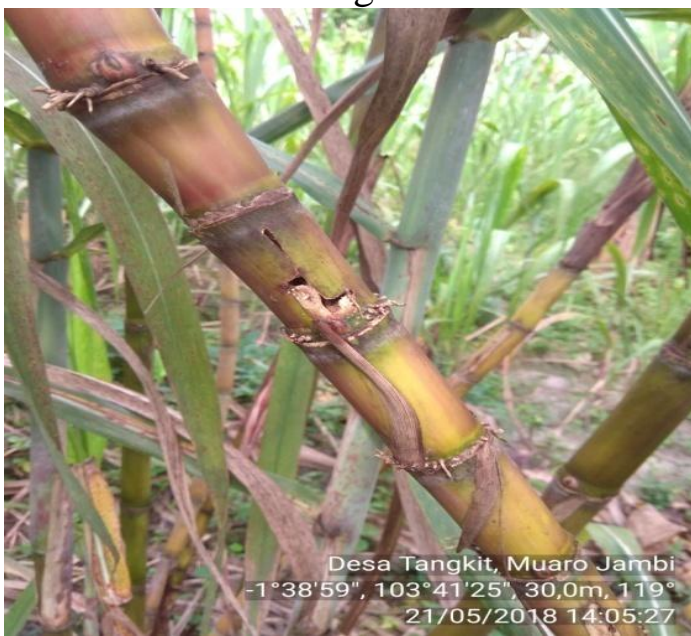

e. Desa Tangkit

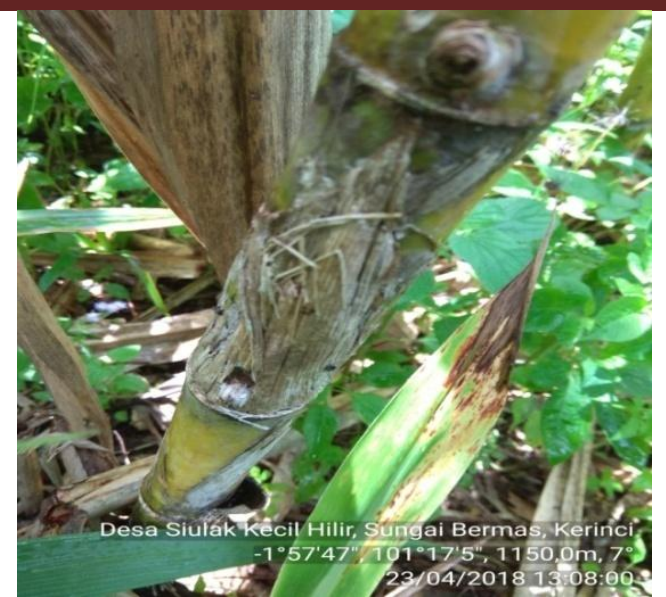

d. Desa Siulak

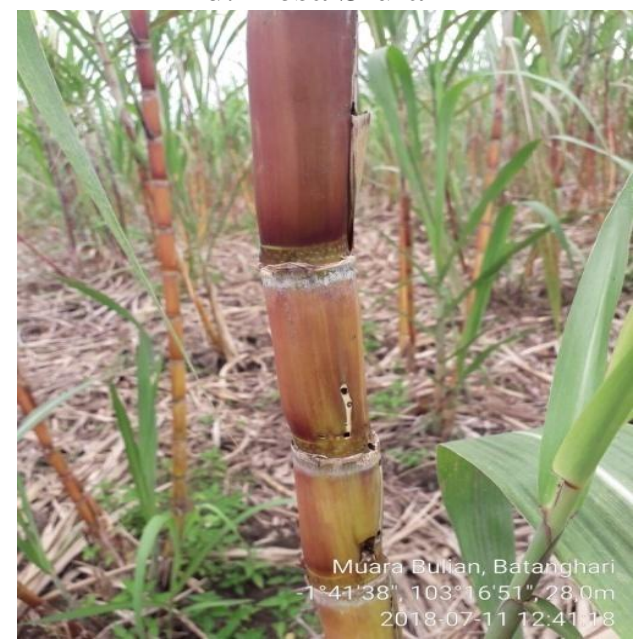

f. Desa Sungai Buluh

Gambar 1. Gejala serangan Hama Penggerek Batang Tebu pada beberapa lokasi di Provinsi Jambi

\section{Hama yang Ditemukan pada Tanaman Tebu}

Berdasarkan pengamatan dan identifikasi seluruh gejala serangan hama yang ditemukan pada tanaman tebu di semua lokasi yang disurvei, adalah sama yaitu penggerek batang tebu yang disebabkan penggerek batang Kumbang (Rhabdoscelus obscurus) (termasuk dalam family Curculionidae) dan subfamily Rhynchophorinae (Gambar 2a.). Hama tersebut diindikasikan merupakan hama utama pada tanaman tebu yang pradewasanya dikenal juga dengan hama uret. Hama uret ini dapat merusak bagian dalam batang tanaman tebu hingga menyebabkan kematian (Gambar 2b). Jenis penggerek batang ini berbeda dengan dengan jenis penggerek yang telah telah dilaporkan oleh Subiyakto (2016). Zimmerman (1968) menyebutkan bahwa ada sepuluh spesies Rhynchophorine terpantau di Polynesia Tenggara dan $R$. Obscurus dinyatakan menyerang tanaman tebu. 
Jurnal Media Pertanian Vol. 4 No. 1 Tahun 2019 Hal. 1 - 7

Media Komunikasi Hasil Penelitian dan Review Literatur Bidang Ilmu Agronomi

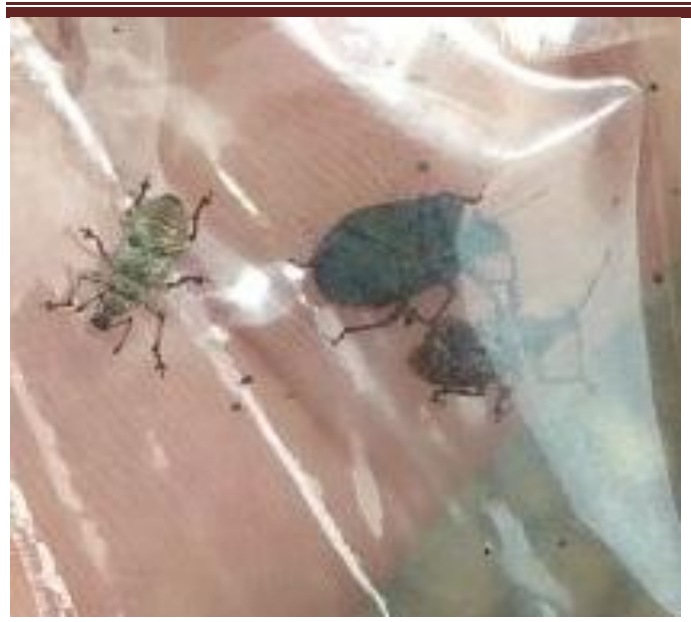

a. Rhabdoscelus Obscurus

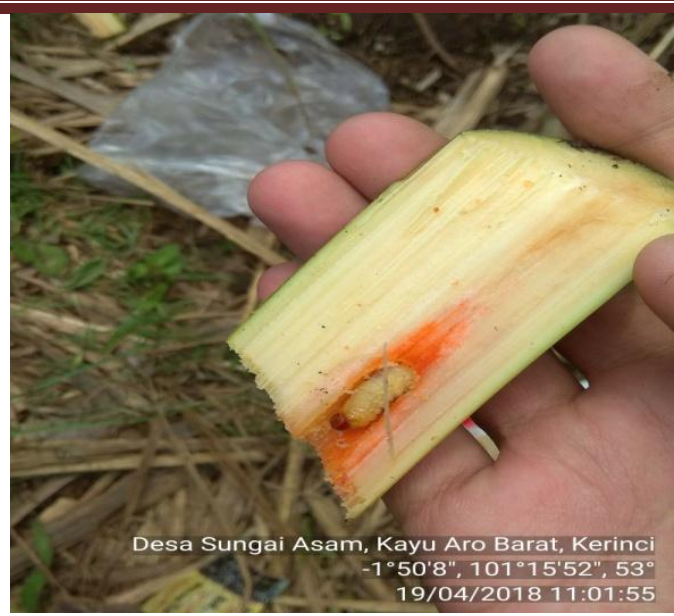

b. Uret Andong-Andong

Gambar 2. Hama yang ditemukan merusak tanaman tebu

\section{Serangan Hama dan Pengendaliannya Menurut Persepsi Petani}

a. Serangga Yang Menyerang Tanaman Tebu Berdasarkan Persepsi Petani

Hama yang menyerang tanaman tebu menurut persepsi petani di masingmasing daerah penelitian dapat dilihat pada Tabel 1

Tabel 1. Serangga Yang Menyerang Tanaman Tebu Berdasarkan Persepsi Petani

\begin{tabular}{cccc}
\hline Nama Petani & Daerah & Jenis & Status \\
\hline Paris & Desa Sungai Asam 1 & Kumbang dan Uret & Hama \\
Eryanto & Desa Sungai Asam 2 & Kumbang dan Uret & Hama \\
Sucipto & Desa Sungai Asam 3 & Uret & Hama \\
Dari & Desa Siulak & Semut & Tidak Hama \\
Parsih & Desa Tangkit & Semut & Tidak Hama \\
Nasution & Desa Sungai Buluh & Semut & Tidak Hama \\
\hline
\end{tabular}

Berdasarkan Tabel 1, tiga orang petani menyebutkan bahwa serangga yang menganggu tanaman tebu adalah semut, dua petani menyebutkan serangga penganggu tanaman tebu adalah adalah hama kumbang dan uret dan satu petani menyebutkan hama penganggu tanaman tebu adalah uret. Serangga yang berstatus hama adalah serangga kumbang dan uret.

\section{b. Pencegahan dan Pengendalian Hama Yang Dilakukan Petani}

Sebagian besar petani di enam lokasi penelitian mengatakan bahwa pengendalian yang dilakukan hanyalah sebatas sanitasi dan membuang bagian tanaman tebu yang terserang hama, belum menggunakan senyawa kimia pestisida. Pestisida yang digunakan hanya sebatas herbisida untuk memberantas gulma.

\section{c. Ciri-ciri Tanaman Tebu Yang Terserang Hama Persepsi Petani}

Petani di Desa Sungai Asam dan Desa Sungai Bermas menyebutkan ciriciri tanaman tebu yang terserang hama adalah menunjukkan batang yang mudah rebah atau busuk pada pangkal batang, selain itu tanaman tebu juga menunjukkan layu daun dan tumbuh kerdil. Petani tebu di Desa Tangkit dan Desa Sungai Buluh 
Jurnal Media Pertanian Vol. 4 No. 1 Tahun 2019 Hal. 1 - 7

Media Komunikasi Hasil Penelitian dan Review Literatur Bidang Ilmu Agronomi ISSN print $2503-1279$

ISSN online $2581-1606$

mengatakan bahwa ciri utama tanaman tebu yang terserang hama adalah batang yang kerdil dan tumbuh membengkok.

\section{d. Bagian Tebu Yang Sering Terserang Hama}

Bagian tanaman tebu yang sering terserang hama berdasarkan persepsi petani di masing-masing daerah penelitian dirangkum pada Tabel 2.

Tabel 2. Bagian Tebu yang Sering Terserang Hama menurut Persepsi Petani

\begin{tabular}{ccc}
\hline Nama Petani & Daerah & Bagian Terserang Hama \\
\hline Paris & Desa Sungai Asam 1 & Batang \\
Eryanto & Desa Sungai Asam 2 & Batang \\
Sucipto & Desa Sungai Asam 3 & Batang \\
Dari & Desa Siulak & Batang \\
Parsih & Desa Tangkit & Batang \\
Nasution & Sungai Buluh & Batang \\
\hline
\end{tabular}

Berdasarkan Tabel 2, enam petani menyebutkan bahwa bagian tanaman tebu yang sering terserang hama adalah bagian batang, sesuai dengan gejala serangan hama dari hasil penelitian.

\section{KESIMPULAN}

Hasil identifikasi menunjukkan penyebab dari serangan penggerek batang tebu adalah Kumbang (Rhabdoscelus obscurus) termasuk dalam family Curculionidae dan subfamily Rhynchophorinae Ordo Coleoptera, diindikasikan hama tersebut merupakan hama utama pada tanaman tebu yang pradewasanya dikenal juga dengan hama uret. Hama uret ini dapat merusak bagian dalam batang tanaman tebu hingga menyebabkan kematian. 
Jurnal Media Pertanian Vol. 4 No. 1 Tahun 2019 Hal. 1 - 7

Media Komunikasi Hasil Penelitian dan Review Literatur Bidang Ilmu Agronomi

ISSN online $2581-1606$

\section{DAFTAR PUSTAKA}

Arista, Y., Wijaya KA, dan Slameto, 2015. Morfologi dan Fisiologi Dua Varietas Tebu (Saccharum Officinarum L.) Sabagai Respon Pemupukan Silika. Fakultas Pertanian, Universitas Jember. Jember.

Direktorat Jendrel Perkebunan, 2014. Statistik Perkebunan Indonesia 2012-2015. Jakarta.

Dinas Perindustrian dan Perdagangan Provinsi Jambi, 2017. Buku Data Base Potensi Komoditi Industri Agro. Jambi.

Epati R. 2012. https://roniepati.wordpress.com/2012/01/30/jenis-gula// Diakses 23 November 2018.

Hakim M. 2010. Potensi Sumber Daya Lahan untuk Tanaman Tebu di Indonesia. Jurnal Agrikultura. 20(1) : 5-12

Hasyim A., Boy A., dan Hilman Y,. 2010. Respons Hama Lalat Buah Jantan terhadap beberapa Jenis Aktraktan dan Warna Perangkap di Kebun Petani. Jurnal Hort 20(2):164-170.

Indrawanto C., Purwono, Siswanto, Syakir M., dan Rumini W. 2010. Budidaya dan Pasca Panen Tebu. ESKA Media. Jakarta.

Rokhman H., Taryono, dan Supriyana. 2014. Jumlah Anakan dan Rendemen Enam Klon Tebu (Saccharum Officinarum L.) Asal Bibit Bagal, Mata Ruas Tunggal, dan Tunas Tunggal. Junal Vegetalika, 3(3) : 89-96

Subiyakto, 2016. Hama Penggerek Tebu dan Perkembangan Teknik Pengendalianya. Jurnal Pertanian Litbang 35 (4) 179-186. Malang.

Tasri E. S, 2017. Metodelogi Penelitian Ekonomi dan Bisnis. Bung Hatta Universitas Press. Padang.

Zimmerman E. C, 1968. Rhynchophorinae of Shoutheastern Polysenia. Jurnal 10(1) 47-77. Polysenia 